\title{
Ethnobiology and research on Global Environmental Change: what distinctive contribution can we make?
}

Ana Haydeé Ladio ${ }^{1, *}$

\begin{abstract}
Several reports have shown that communities of small farmers are the most vulnerable to global environmental change (GEC). Others have revealed that societies which can count on a rich body of traditional ecological knowledge (TEK) are more resilient in facing this challenge, since their behaviour is already adaptive in character. Within this scenario, the IPCC establishes the need for "cross fertilisation" between TEK and scientific knowledge (SK). But how can we arrive at interpretative agreements when these two knowledge systems are so different? In this review I analyse the substantial role ethnobiology can play in providing empirical evidence on this subject in Latin America. The characteristics of our discipline offer differential advantages: 1 ) because we are actually there, our interpretation of vulnerability and adaptation arise from experiences shared with people who have a long term interconnection with their environment, and not from abstract indices created in offices; 2 ) because we work on a community scale, at a local level, and the most appropriate approach in search of solutions should be bottom-up and not top-down; 3) because we are academically trained as interlocutors, and 4) because our approach is rooted in a vision of the landscape as a cultural construction. Ethnobiologists must come to operational agreements on how to deal with GEC, and set down guidelines for a reconciliatory dialogue between SK and TEK, a process which should not be considered something easy or quick, but a long-term process which is just in its infancy.
\end{abstract}

Keywords: Local Level, Vulnerability, Multicultural Dialogue

${ }^{1}$ INIBIOMA, CONICET, Universidad Nacional del Comahue, CRUB. Quintral 1250. SC de Bariloche (8400). Río Negro. Argentina.

* — E-mail address: ahladio@gmail.com 


\section{An added dimension to the study of climate change}

The effects of global environmental change (GEC) present one of the biggest challenges faced by humanity, and according to technical reports, communities of poor small farmers are the most vulnerable group (Pyhälä et al. 2016). GEC refers to changes at a local, regional and/or large scale in the geosphere and biosphere, the result of complex, accumulative, multiple processes where the human being plays a substantial role (IPCC 2014). Despite this, research has focused mainly, although not exclusively, on global modelling techniques from a top-down perspective that focus on biophysical aspects and have little to offer on a local level (Arce-Nazario 2007).

Several authors have drawn attention to the need for inclusion of traditional ecological knowledge (TEK) (Berkes and Ross 2016), so as to improve understanding of GEC through new elements, and validate (or revoke) the data from instrumental models (Leonard et al. 2013; Tengö et al. 2014). Others indicate that the principal contribution of TEK in the study of GEC is to inform us of the perceptions of those who, at the end of the day, make the decisions on behaviour and action in the face of this change (Byg and Salick 2009; FernándezLlamazares et al. 2015; FernándezLlamazares et al. 2016).

Various studies have shown that societies which are rich in TEK are more resilient when faced with change (Ford et al. 2006). Local knowledge obtained through long-term experience and observation provides a basis for adaptation and innovation. On the Northern Bolivian Altiplano, for example, farmers' use of biodiversity in adaptation to GEC is related to the use of drought and frost tolerant crops, improvements in soil and water management, and planting across different microenvironments to disperse risk and take advantage of spatial heterogeneity (Meldrum et al. 2017). In addition, self organization, reciprocity and cohesion, which form part of the principal social and ethical guidelines of TEK, constitute an important part of adaptive capacity, according greater governance over natural resources (Berkes and Ross 2016; Ruiz-Mallén et al. 2017).

A recent review on GEC and local perceptions (Pyhälä et al. 2016) which included 126 articles, shows that in spite of the interest described above, studies are still few and far between, principally on the American continent. Due to the multifaceted character of GEC and the difficulties encountered when trying to isolate drivers, the authors recommend that systemic approaches be used rather than classic Cartesian methods, and that local cosmologies should be taken into account. They strongly encourage the co-production of intercultural work protocols, employing standard methodologies that include quantitative approaches which can be reproduced in cross cultural studies, plus qualitative analyses that can simultaneously reflect cultural diversity.

In addition, both in this review and in other works, we have been urged to reflect on the tension that exists between TEK and scientific knowledge (SK) (Byg and Salick 2009; Fernández-Llamazares et al. 2015). This is not only because of epistemological discrepancies, but is mainly due to the power plays that underlie this relationship, which constantly discredit and devalue TEK and place it in a subordinate position to SK. Consequently, it is possible that even if research on TEK and GEC increase in volume, the results may be dismissed. Or, perhaps more dangerously, this information may be rationalised/fragmented using 
categories and logic originating in western epistemology, and will therefore not reflect true local perceptions (Ruiz Pérez and Argueta Villamar 2011).

Faced with this scenario, the IPCC (2014) established the need for "cross fertilisation" between TEK and SK, and the importance of defining action to moderate harm or take advantage of opportunities offered by actual or anticipated climate conditions to build adaptive capacity (Tengö et al. 2014). In relation to this, Davis and Ruddle (2010) highlighted the urgent need for studies on TEK to be credible and provide reliable and meaningful information.

Considering all these ideas and proposals for the future, I ask myself how we can come to interpretative agreements on GEC when two very different knowledge systems are involved. Are we willing to listen and value other voices without everything being "reduced" to western logic? What trustworthy empirical data are necessary for us to obtain evaluations that can guide us to real solutions for GEC?

In this context, the discipline of ethnobiology has a unique opportunity to contribute to the study of GEC processes. Due to its systemic nature and varied, transdisciplinary approaches (qualitative, quantitative and/or mixed) it can provide valuable empirical evidence on GEC. In particular, the notable Latin American biocultural diversity which is present principally in rural communities, although also in the big cities, offers a unique scenario for understanding processes of adaptation to change, the application of TEK and its hybridisation with SK (FernándezLlamazares et al. 2015). Due to certain historical, political and social circumstances throughout the length and breadth of Latin America there are areas where TEK has resisted colonial processes, re-shaping and re-establishing itself in the face of change (Ladio and Albuquerque 2014). In the following paragraphs I would like to highlight the differential advantages ethnobiology can offer in the context of GEC research in Latin America:

\section{Ethnobiology is inclusive}

Research on GEC has rarely included local perspectives; to be precise, human experience has been excluded, and studies have focused on the use of quantitative indices that give an indirect measure of vulnerability (Arce-Nazario 2007), or of societies' capacity to adjust (Holland et al. 2016). This would seem paradoxical, given that we humans are the central players in GEC, both as perpetrators and victims. In order to register human experience, one must "be there", on site, vividly sharing the local experience (Roncoli 2006), and in these situations the qualitative and quantitative methodologies of ethnobiology are solid tools for the work of visibilizing the people's perspective.

The ethnobiological study of TEK together with local communities, both in empirical and conceptual terms, adds a holistic approach to climate change that no other data set can provide. For example, our ethnobiological field experience reveals that when we work with narratives and observation the narratives we obtain are socio-environmental in character, in the sense that the factual accounts relating to environmental change (i.e. rainy years, rivers bursting their banks and/or poor harvests, successful good lambing, etc.) are inextricably woven into family histories (i.e. migrations, journeys, associations with neighbours, illness, etc.). These changes in turn are amalgamated with landscape changes, revealing a process of change that can be completely 
reconstructed. TEK observations create a diachronic database; that is, a record of continuous observations from a single local/individual over a long time period - a long term pattern-data (Whyte 2013).

In addition, "being there" gives us an opportunity to systemize environmental information on the changes that have taken place in the landscape with the biologicalecological methodologies we use, information that can complement and complete the big picture. This distinguishes us clearly from the exclusively social approaches, as we can integrate casuistic information of a biocultural nature.

Another great advantage of "being there" is that local perceptions are recorded through ethnobiology fieldwork; during the interviews or workshops locals are given the opportunity to interpret and question their own experience in relation to their environment, and reflect on their problems, their vulnerability and their capacity to make adjustments. Ethnobiology, therefore, is not only able to enrich research with a greater level of socio-environmental complexity, but also favours a more inclusive agenda, generating instances of self-evaluation and empowerment for participants (Arce-Nazario 2007).

For example, local inhabitants in the rural Pilcaniyeu community (Rio Negro, Patagonia) were empowered by our work with them on the use of medicinal wild plants. As a result of the participative workshops during which locals identified 10 wild plants which were difficult to collect due to their scarcity, since 2005 they have been reproducing these species by seed and cuttings collected in the area, using greenhouses belonging to the community. The plants are then shared out, ensuring a steady supply for everyone.

\section{The ethnobiology scale takes a "bottom-up" approach}

The scale of ethnobiological research is local, "fine grain", unlike the quantitative models used in the study of GEC, which are mainly "course grain", and come generally from SIG (Smit and Skinner 2002). This is why ethnobiological studies present substantial empirical identification of forcing factors from the community perspective, and not from mechanistic presumptions, which often have little to do with local socioenvironmental reality. Ethnobiological research, then, takes a bottom-up approach, in contrast to the more classical, expanded, top-down approaches. In this sense, a reduction in scale is essential in order to find solutions that take local cosmologies into account in an inclusive way. There is empirical evidence which shows that the biocultural indicators used by local Latin American communities to identify short and long term changes on a local scale could be used as additional indicators of great predictive value (Fernández-Llamazares et al. 2015; Ruiz-Mallén et al. 2017).

For example, Castillo and Ladio (2017) have shown how TEK possessed by Patagonian rural farmers provides specific tools for the interpretation and prediction of the future of their herds and fate of their lands. Thirty signs given by 18 different animals (15 wild and 3 domestic) were described, where domestic animals are important mainly as ethno-indicators of longterm biophysical changes, and wild animals are mainly important in marking short-term biophysical changes or as sociocultural indicators. These ethnoindicators enable farmers to face inclement weather and other unexpected climatic events, as well as environmental and socioeconomic change. 


\section{Ethnobiologists are interlocutors}

Although different multilateral organisms have insisted on greater pluralism to resolve environmental problems, up to now this has had little operative success (Tengö et al. 2014). For this reason, the role of ethnobiologists can open the way to more valuable dialogue. Due to their transdisciplinary training, ethnobiologists experience the tension between SK and TEK constantly. It is true that their position has changed over time in terms of the objectives of their research, but from my point of view, there is no doubt that their role as interlocutors is of considerable importance at the present time.

Like all ethnoscience, ethnobiology questions the rationality which seems to be accepted as universal (the only model) by western science, and in recent years has fought for pluralistic solutions to environmental problems (Ruiz Pérez and Argueta Villamar 2011). According to Leff (2007), we ethnobiologists have learned that environmental complexity goes beyond the field of scientific logos and that only by means of dialogue between different knowledge systems, where diverse rationalities and cultural imaginaries come together, can we arrive at any understanding.

In this work of interlocution it is necessary to differentiate two knowledge systems linked to Nature and its management. The dominant knowledge system, SK, which belongs to western-urban society, with a dualist cosmovision that separates Nature from Culture, and the TEK system commonly found in original-traditional-rural societies where the Nature-Culture relationship takes precedence, and where biodiversity is maintained through management practices and social networks (Delgado and Escóbar
2006). From a relationist perspective, biodiversity is animated and the players which are active in the processes involved include both natural and supernatural forces (Aigo and Ladio 2016).

Scientific bodies of knowledge are based on universalism, the idea of the existence of universal truths. It is an abstract, globalising kind of knowledge that looks for general patterns. In contrast, TEK is based on particularism, and the knowledge is situated, rooted in local experience. In other words, TEK and SK are dissenting systems, although this does not mean they are incompatible, isolated or static. TEK and SK, although asymmetrical in power, are both permanently subject to processes of hybridisation and porosity, which shorten or lengthen the distance between them. The discrepancies mentioned above make plain that ethnobiology should generate a protocol for arriving at interpretative agreements between TEK and SK, which do not merely entail a "translation", but mechanisms which promote horizontal dialogue. It is essential to identify the drivers of change, the magnitude of the threat, and the sensitivity and adaptive capacity of each society from the logic of the local perspective, and not from indices developed in offices.

For example, the ethnoecological work of Aigo and Ladio (2016) has contributed to freshwater resource management by providing empirical evidence of the critical role of local perceptions in promoting sustainable management of natural resources. This investigation has shown that Mapuche traditional cosmovision on the use of fish and waters, a relationist vision which promotes respect and avoidance of actions that could disturb the beings (animals and sacred or mythological characters) that inhabit and take care of them, should be fostered as part of 
"scientific" management plans for CONCLUSIONS

Patagonian natural resources.

Ethnobiology sees the landscape as a socio-cultural construction

Ethnobiology has provided ample evidence that the principal biodiverse landscapes have been moulded by human action since pre-Columbian times, demythologising the paradigm of "pristine landscapes" (Lins Neto et al. 2014). Climate change studies are led mainly by ecologists, biologists and climatologists. The education and academic practice of these professionals reflects the dualist premise that separates the human being from Nature (Sedrez dos Reis et al. 2014). This conception would be opposed by the majority of ethnobiologists, who have been arguing for years that settlements and landscapes have been domesticated through human practices which tend to maintain environmental diversity and the renewal of ecological cycles, adapting to the changing conditions of their surroundings (Levis et al. 2017). Having learned from local communities, the ethnobiological approach considers the landscape to be a cultural construction, a product of different management intensities, in situ and ex situ, which include tolerance, protection, enhancement and cultivation or breeding, and depend directly on the cosmovision of the societies administrating them (many Latin American case studies in Casas et al. 2017). The study of change in these practices is an ideal heuristic framework for the analysis of adaptation strategies in the face of GEC, which can not only be applied at a local level, but allows cross cultural comparison. This comparative approach, however, has not yet been applied.
The conceptual and methodological frameworks developed by ethnobiology offer differential advantages for the study of GEC. Nevertheless, operational agreements still have to be constructed so that our contributions are valued sufficiently in international literature. Long-term baseline and monitoring studies must be coordinated with local communities, where prospective and retrospective visions can be articulated effectively. In the particular case of Latin America, with its immeasurable biocultural diversity, the call for this kind of long-term work inspires us to rethink our professional practices.

It is terribly important that these studies not succumb to the temptation of reproducing the model that is common in scientific literature, which has fragmented TEK into "useful" and "useless" categories, valorising the components that most resemble scientific information and implicitly disregarding other elements that scientists consider belong to the realm of superstition and belief. It is also necessary to reflect on the existence of sensitive information in the TEK systems, which must be protected from unauthorized public disclosure, and ethnobiologists have the difficult task of seeing that this is respected in South America. Only collaborative and active assessment of independently validated knowledge bases through consensus debates can produce trustworthy data on GEC. Improved understanding and visibilization of TEK can set out the foundations for reconciliatory dialogue between SK and TEK, a process which should not be considered as something easy, but as a long term process which is just beginning. Finally, I consider that ethnobiology should be rooted more strongly 
in experiential work and shared reflection, mechanisms which allow us to recover the strength of our feelings, and therefore learn from one another.

\section{ACKNOWLEDGEMENTS}

This study was funded by PICT 20121073 of the Agencia Nacional de Promoción Científica y Tecnológica (ANPCyT) and by Consejo Nacional de Investigaciones Científicas y Técnicas (PIP 0466-CONICET).

\section{REFERENCES}

Aigo J, Ladio A (2016) Traditional Mapuche ecological knowledge in Patagonia, Argentina: fishes and other living beings inhabiting continental waters, as a reflection of processes of change. Journal of Ethnobiology and Ethnomedicine 12: 56

Arce-Nazario JA (2007) Landscape images in Amazonian narrative: the role of oral history in environmental research. Conservation and Society 5: 115-133

Berkes F, Ross H (2016) Panarchy and community resilience: Sustainability science and policy implications. Environmental Science \& Policy 61: 185-193

Byg A, Salick J (2009) Local perspectives on a global phenomenon-Climate change in Eastern Tibetan villages. Global Environmental Change 19: 156-166

Casas A, Torres-Guevara J, Parra F (2017) Domesticación en el Continente Americano. Historia y perspectivas del manejo de recursos genéticos en el Nuevo Mundo. Universidad Agraria La Molina. IIES, Lima, Perú

Castillo L, Ladio A (2017) Mammals and birds as ethnoindicators of change: their importance to livestock farmers in Arid Patagonia (Argentina). Environment, Development and Sustainability doi10.1007/s10668-017-9983-z

Davis A, Ruddle K (2010) Constructing confidence: Rational skepticism and systematic enquiry in local ecological knowledge research. Ecological Applications 20: 880-894
Delgado F, Escóbar C (2006) Diálogo intercultural e intercientífico para el fortalecimiento de las ciencias de los pueblos indígenas originarios. 1ed. Agrupo, Cochabamba, Bolivia

Fernández-Llamazares A, Díaz-Reviriego I, Guéze M, Cabeza M, Pyhälä A, Reyes-García V (2016) Local perceptions as a guide for the sustainable management of natural resources: Empirical evidence from a smallscale society in Bolivian Amazonia. Ecology and Society doi:10.5751/ES-08092-210102

Fernández-Llamazares $A$, Méndez-López ME, Díaz-Reviriego I, McBride MF, Pyhälä A, RosellMelé A, Reyes-García V (2015) Links between media communication and local perceptions of climate change in an indigenous society. Climatic Change 131: 307-320

Ford JD, Smit B, Wandel J (2006) Vulnerability to climate change in the Arctic: A case study from Arctic Bay, Canada. Global Environmental Change 16: 145-160

Holland MB, Shamer SZ, Imbach P, Zamora JC, Medellin Moreno C, Hidalgo EJL, Donatti Cl, Martínez-Rodríguez R, Harvey CA (2016) Mapping adaptive capacity and smallholder agriculture: applying expert knowledge at the landscape scale. Climatic Change doi:10.1007/s10584-016-1810-2

IPCC (2014) Part A: Global and Sectoral Aspects. (Contribution of Working Group II to the Fifth Assessment Report of the Intergovernmental Panel on Climate Change). Climate Change 2014: Impacts, Adaptation, and Vulnerability. [https://www.ipcc.ch/pdf/assessmentreport/ar5/wg2/WGIIAR5-

FrontMatterA_FINAL.pdf] Accessed 17 April 2017 Ladio AH, Albuquerque UP (2014) The concept of hybridization and its contribution to urban ethnobiology. Ethnobiology and Conservation doi:10.15451/ec2014-6-3.3-1-11

Leff E (2012) La complejidad ambiental. Polis doi 10.4000/polis.4605

Leonard S, Parsons M, Olawsky K, Kofod F (2013) The role of culture and traditional knowledge in climate change adaptation: Insights from East Kimberley, Australia. Global Environmental Change 23: 623-632 
Levis C, Costa FRC, Bongers F, Peña-Claros M, Clement CR, Junqueira AB et al. (2017) Persistent effects of pre-Columbian plant domestication on Amazonian forest composition. Science 355: 925-931

Lins Neto EMF, Peroni N, Casas A, Parra F, Aguirre X, Guillén S, Albuquerque UP (2014) Brazilian and Mexican experiences in the study of incipient domestication. Journal of Ethnobiology and Ethnomedicine doi:10.1186/1746-4269-10-33

Meldrum G, Mijatović D, Rojas W, Flores J, Pinto M, Mamani G, Condori E, Hilaquita D, Gruberg $\mathrm{H}$, Padulosi S (2017) Climate change and crop diversity: farmers' perceptions and adaptation on the Bolivian Altiplano. Environment, Development and Sustainability doi:10.1007/s10668-016-9906-4

Pyhälä $A$, Fernández-Llamazares $A$, Lehvävirta H, Byg A, Ruiz-Mallén I, Salpeteur M, Thornton TF (2016) Global environmental change : local perceptions, understandings and explanations. Ecology and Society doi:10.5751/ES-08482-210325

Roncoli C (2006) Ethnographic and participatory approaches to research on farmers' responses to climate predictions. Climate Research 33: 81-99

Ruiz Pérez LM, Argueta Villamar A (2011) Saberes indígenas y diálogo intercultural. Cultura Científica y Saberes Locales 5: 31-56

Ruiz-Mallén I, Fernández-Llamazares A, ReyesGarcía V (2017) Unravelling local adaptive capacity to climate change in the Bolivian Amazon: the interlinkages between assets, conservation and markets. Climatic Change 140: 227-242 doi:10.1007/s10584-016-1831-x

Sedrez dos Reis M, Ladio A, Peroni N (2014) Landscapes with Araucaria in South America: Evidence for a cultural dimension. Ecology and Society 19: 43 doi:10.5751/ES-06163190243

Smit B, Skinner MW (2002) Adaptation Options in Agriculture To Climate Change: a typology. Mitigation and Adaptation Strategies for Global Change 7: 85-114

Tengö M, Brondizio ES, Elmqvist T, Malmer P, Spierenburg M (2014) Connecting diverse knowledge systems for enhanced ecosystem governance: The multiple evidence base approach. Ambio 43: 579-591
Whyte KP (2013) On the role Pyhälä of traditional ecological knowledge as a collaborative concept: a philosophical study. Ecological Processes 2:1-12
Received: 17 April 2017

Accepted: 13 June 2017

Published: 14 July 2017 